\title{
Association of Renal Injury with Increased Oxygen Free Radical Activity and Altered Nitric Oxide Metabolism in Chronic Experimental Hemosiderosis
}

\author{
Xin J. Zhou, Zoltan Laszik, Xiu Q. Wang, Fred G. Silva, and Nosratola D. Vaziri \\ Department of Pathology (XJZ), University of Texas Southwestern Medical Center, Dallas, Texas; Department of \\ Pathology (ZL, FGS), University of Oklahoma Health Sciences Center, Oklahoma City, Oklahoma; and Division of \\ Nephrology and Hypertension (XQW, NDV), University of California at Irvine, Irvine, California
}

SUMMARY: Chronic iron ( $\mathrm{Fe}$ ) overload is associated with a marked increase in renal tissue iron content and injury. It is estimated that $10 \%$ of the American population carry the gene for hemochromatosis and $1 \%$ actually suffer from iron overload. The mechanism of iron overload-associated renal damage has not been fully elucidated. Iron can accelerate lipid peroxidation leading to organelle membrane dysfunction and subsequent cell injury/death. Iron-catalyzed generation of reactive oxygen species (ROS) is responsible for initiating the peroxidatic reaction. We investigated the possible association of oxidative stress and its impact on nitric oxide (NO) metabolism in iron-overload-associated renal injury. Rats were randomized into Fe-loaded (given $0.5 \mathrm{~g}$ elemental iron/kg body weight as iron dextran; IV), Fe-depleted (given an iron-free diet for 20 weeks), and control groups. Renal histology, tissue expression of endothelial and inducible nitric oxide synthases (eNOS and iNOS), renal tissue expression of nitrotyrosine, plasma, and renal tissue lipid peroxidation product, malondialdehyde (MDA), and plasma and urinary NO metabolites (NOx) were examined. Iron overload was associated with mild proteinuria, tissue iron deposition together with significant glomerulosclerosis, tubular atrophy, and interstitial fibrosis. Rare focal glomerulosclerosis and tubulointerstitial changes were noted in normal controls. No renal lesions were observed in Fe-depleted rats. Iron deposits were seen in glomeruli, proximal tubules, and interstitium. The iron staining in the distal tubules was negligible. Both plasma and renal tissue MDA and renal tissue nitrotyrosine were increased significantly in Fe-loaded rats compared with control rats. In contrast, Fe-depleted animals showed a marked reduction in plasma and renal tissue MDA and nitrotyrosine together with significant elevation of urinary NOx excretion. In addition, iron-overload was associated with up-regulation of renal eNOS and iNOS expressions when compared with the control and Fe-depleted rats that showed comparable values. In conclusion, chronic iron overload resulted in iron deposition in the glomeruli and proximal tubules with various renal lesions and evidence of increased ROS activity, enhanced ROS-mediated inactivation, and sequestration of NO and compensatory up-regulation of renal eNOS and iNOS expressions. However, iron depletion was associated with reduced MDA and tissue nitrotyrosine abundance, increased urinary NOx excretion, normal nitric oxide synthase (NOS) expression, and absence of renal injury. These findings point to the possible role of ROS in chronic iron overload-induced renal injury. (Lab Invest 2000, 80:1905-1914).

C hronic iron overload is associated with marked iron deposition in the glomeruli and proximal and distal tubules accompanied by glomerular hypercellularity, mesangial expansion, tubular atrophy, and interstitial fibrosis of the kidneys (Landing et al, 1989; Pardo-Mindan et al, 1990; Zhou, et al, 1996). It is now known that approximately $10 \%$ of the American population carry the gene for hemochromatosis, and 1\% actually suffer from iron overload (Edwards et al, 1991). The underlying mechanism of iron overloadassociated renal damage has not been fully elucidated. As an electron donor, ferrous iron catalyzes the Fenton reaction, which leads to generation of the highly reactive cytotoxic hydroxyl radicals. Increased lipid peroxidation has been previously shown to occur in the kidneys of experimental animals with iron over-

Received August 31, 2000.

Address reprint requests to: Dr. Xin J. Zhou, Department of Pathology, University of Texas Southwestern Medical Center, 5323 Harry Hines Boulevard, Dallas, TX 75390-9073. E-mail: joseph.zhou@utsouthwestern.edu load (Goldberg et al, 1962; Preece et al, 1988). Peroxidatic decomposition of the polyunsaturated fatty acids of organelle membrane phospholipids would result in specific abnormalities of organelle function leading to cell injury/cell death (Bacon and Britton, 1989; Halliwell and Gutteridge, 1985). It is known that the reactive oxygen species (ROS) can initiate the peroxidatic reaction (Halliwell and Gutteridge, 1985). Increased ROS activity is also suspected as an important factor in the progression of renal disease and, in particular, nephrosclerosis (Gonick et al, 1996; Shah, 1989). In addition, increased ROS can contribute to associated renal injury by inactivating nitric oxide (NO) (Bosse and Bachmann, 1997; Heeringa et al, 1998; MacMillan-Crow et al, 1996; Myers et al, 1995; Vaziri et al, 1999b). It has been suggested that NO deficiency can cause a variety of renal injuries (Baylis et al, 1992; Fujihara et al, 1994; Ribeiro et al, 1992; Yamada et al, 1996). Based on these observations, we hypothesized that chronic iron overload-induced renal damage may be, in part, due to increased generation of 
Table 1. Body Weight, Creatinine Clearance, and Urinary Protein Excretion in Study Groups at the End of 20 Weeks

\begin{tabular}{lccc}
\hline \multicolumn{1}{c}{ Group } & $\begin{array}{c}\text { Body weight } \\
(\mathrm{g})\end{array}$ & $\begin{array}{c}\text { Creatinine } \\
\text { clearance } \\
(\mathrm{ml} / \mathrm{min})\end{array}$ & $\begin{array}{c}\text { Urinary protein } \\
(\mathrm{mg} / 24 \mathrm{hrs})\end{array}$ \\
\hline Control & $460 \pm 12$ & $2.7 \pm 0.2$ & $36.3 \pm 2.3$ \\
Fe-loaded & $468 \pm 5$ & $2.2 \pm 0.2$ & $60.5 \pm 3.5^{\star}$ \\
Fe-depleted & $414 \pm 12^{\star}$ & $2.4 \pm 0.1$ & $43.2 \pm 2.8$ \\
\hline
\end{tabular}

Data are mean $\pm \mathrm{SE} ; n=6$ in each group.

${ }^{*} p<0.05$ vs other groups.

ROS and associated reduction in NO availability. Furthermore, the exact localization of renal tubular hemosiderin deposition remains controversial. We, therefore, sought to determine the location of hemosiderin deposition by the lectin dissection method (Silva et al, 1993) in rats with experimental hemosiderosis.



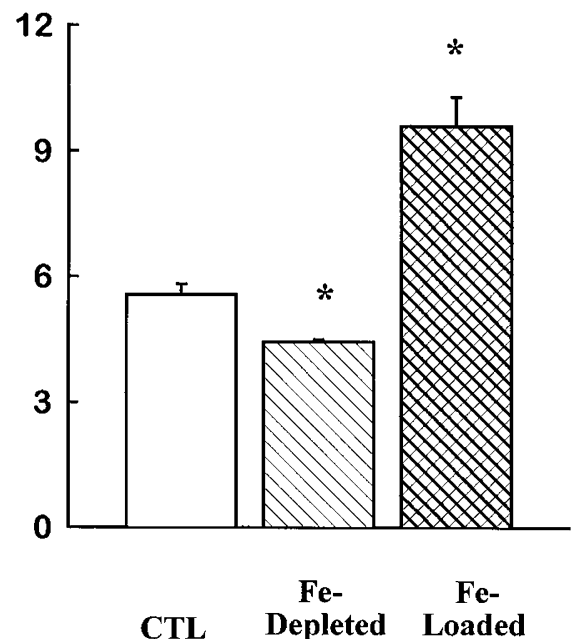

CTL Depleted Loaded

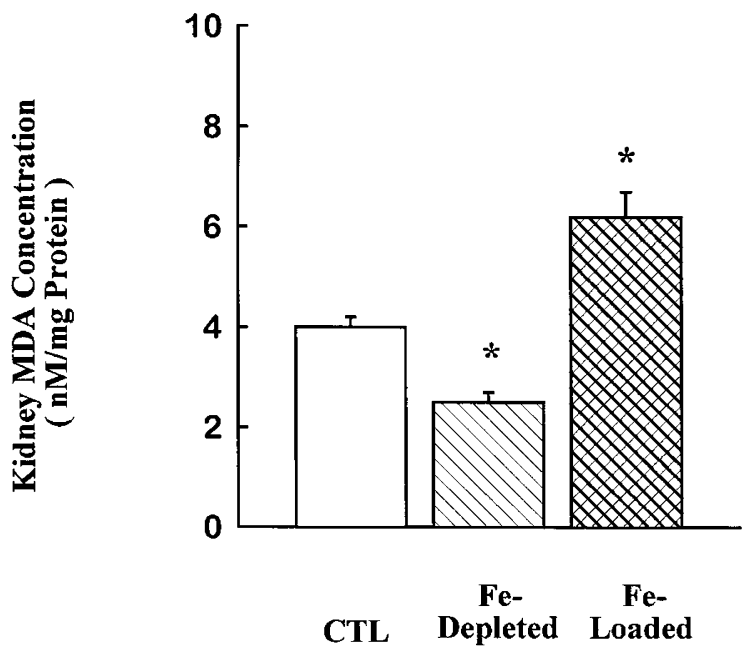

Figure 1.

Plasma (upper panel) and renal tissue (lower panel) malondialdehyde (MDA) levels in control, iron (Fe)-loaded, and Fe-depleted rats at the end of 20-week observation period. $n=6$ in each group; ${ }^{*} p<0.05$ vs other groups.

\section{Results}

\section{General Data}

Iron-depleted animals showed a mild and statistically insignificant reduction in food intake $(17.6 \pm 0.7,19.6$ \pm 0.5 , and $20.4 \pm 1.1 \mathrm{~g}$ food/day in Fe-depleted, Fe-loaded, and control animals, respectively; $p=$ not significant) and a significantly lower body weight at the end of the observation period when compared with the other groups that showed comparable values (Table 1). Urinary protein excretion was significantly higher in the Fe-loaded rats compared with both the control and Fe-depleted groups. No differences were found among the three groups in creatinine clearance.

\section{Biochemical Measurements}

Both plasma and renal tissue malondialdehyde (MDA) concentrations were increased significantly in $\mathrm{Fe}$ -
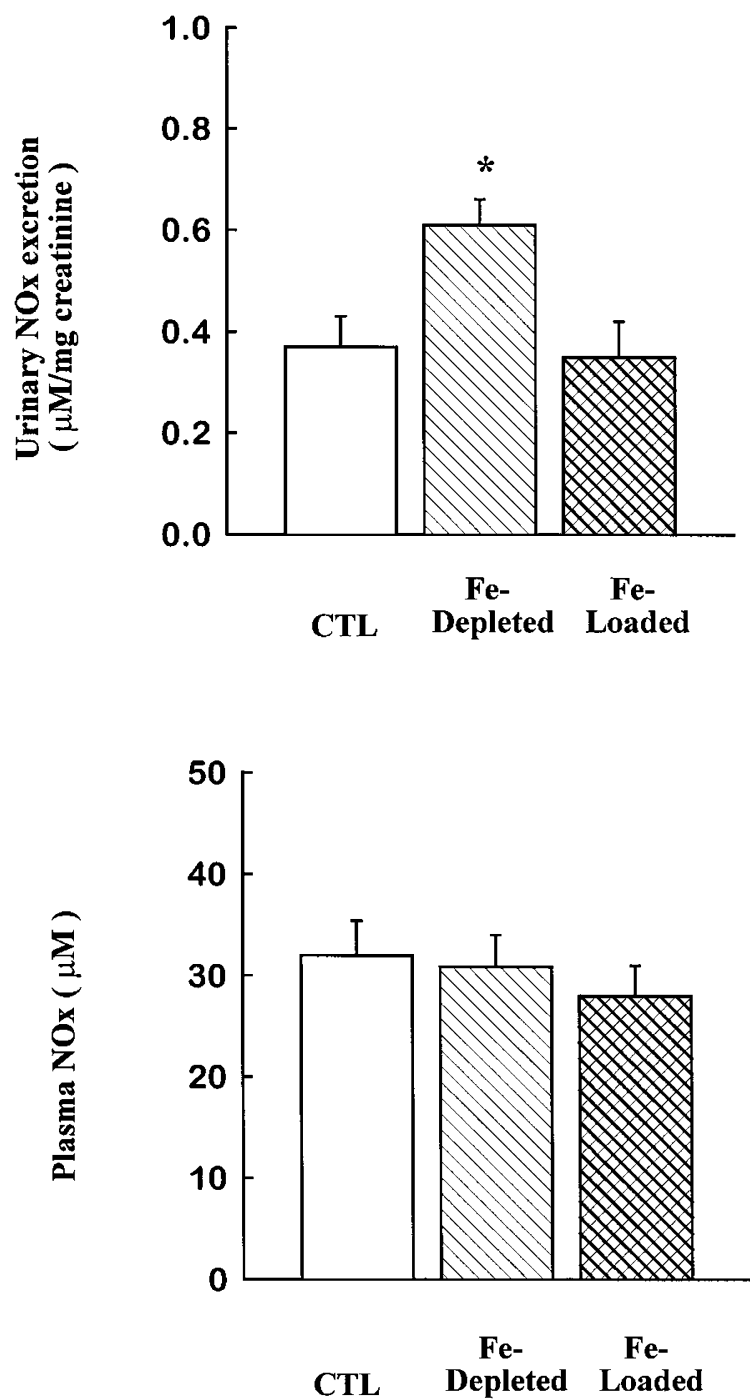

Figure 2.

Plasma concentration and urinary excretion of NO metabolites, nitrates, and nitrites (NOx), in control, Fe-loaded, and Fe-depleted rats at the end of 20-week observation period. $n=6$ in each group; ${ }^{*} p<0.05$ vs other groups. 

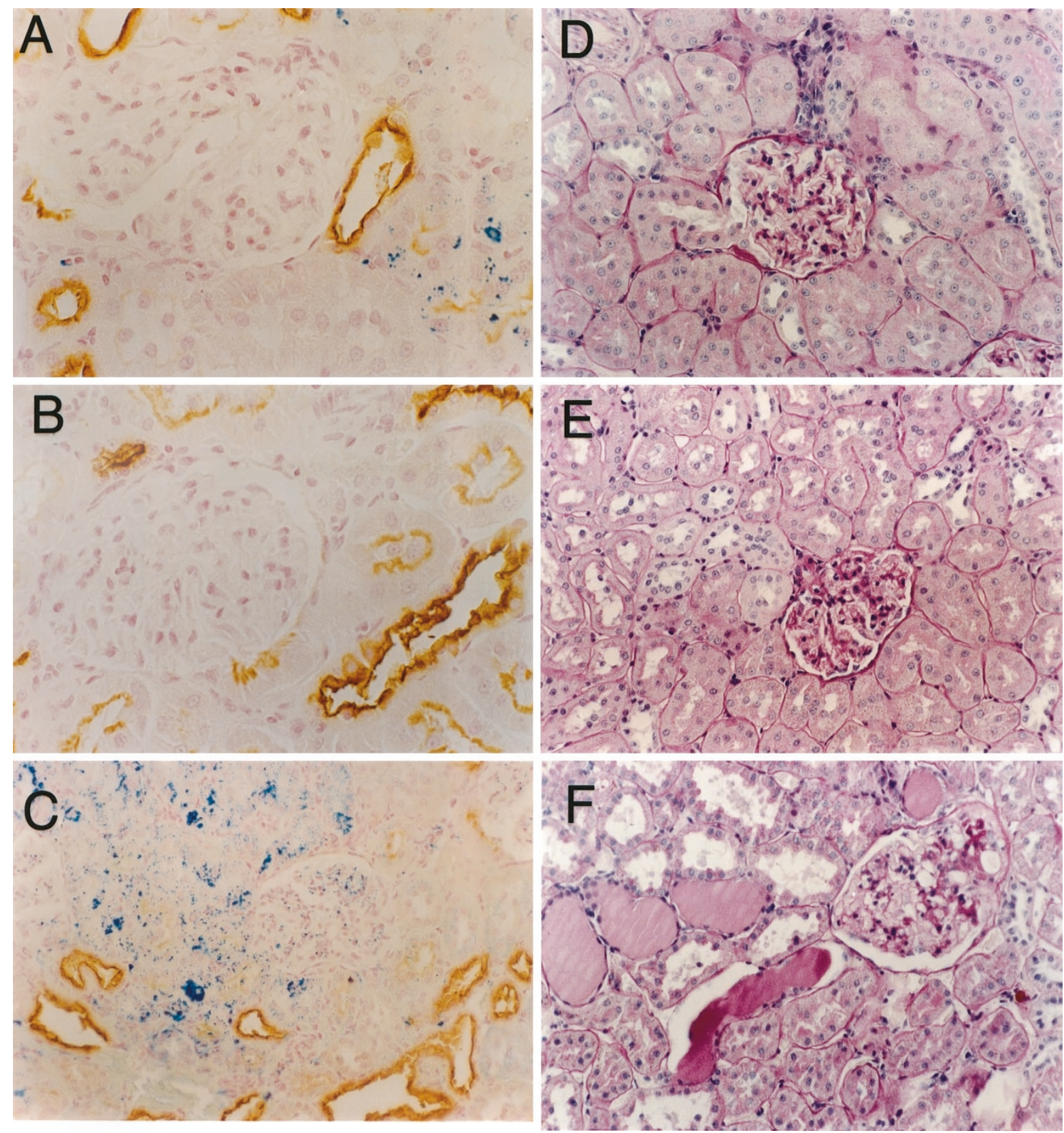

\section{Figure 3.}

Histopathology and lectin studies. $A$ to $C$, Double stains for iron and Arachis Hypogaea (AH) lectin (marker of distal tubules and collecting ducts) in control ( $A$ ), Fe-depleted $(B)$, and Fe-loaded animals $(C)$. Note that iron is deposited in the AH-negative proximal tubules of the kidneys both in the control $(A)$ and Fe-loaded $(C)$ animals. The kidneys in Fe-loaded animals reveal more prominent tubular and interstitial iron depositions. $D$ to $F$, Histologic features of the kidneys in control $(D)$, Fe-depleted $(E)$, and Fe-loaded animals $(F)$. Both the control $(D)$ and the Fe-depleted rats $(E)$ show essentially normal histology of the kidney. The microphotograph from the Fe-loaded animals depicts some of the most characteristic light microscopic changes of the kidney, including extensive cast formation of the tubules and segmental sclerotic lesions in the glomerulus.

loaded animals when compared with those observed in the normal and Fe-depleted groups. The Fedepleted group showed significantly lower plasma and renal tissue MDA levels than normal controls (Fig. 1). Urinary NO metabolites (NOx) excretion in the Fedepleted animals was significantly higher than that observed in the control and Fe-loaded groups that showed comparable values (64.4 \pm 7.3, $42.4 \pm 4.9$, and $38.4 \pm 4.6 \mu \mathrm{M} / 24$ hours in Fe-depleted, Feloaded, and control animals, respectively; $p<0.05$ ).
Table 2. Iron Deposition and Renal Injury Scores in the Study Groups

\begin{tabular}{lccc}
\hline \multicolumn{1}{c}{ Group } & $\begin{array}{c}\text { Iron } \\
\text { deposition }\end{array}$ & $\begin{array}{c}\text { Glomer- } \\
\text { ulosclerosis }\end{array}$ & $\begin{array}{c}\text { Tubulointerstitial } \\
\text { lesions }\end{array}$ \\
\hline Control & $0.67 \pm 0.21$ & $0.33 \pm 0.21$ & $0.83 \pm 0.31$ \\
Fe-loaded & $2.6 \pm 0.24^{*}$ & $1.40 \pm 0.24^{*}$ & $2.40 \pm 0.40^{*}$ \\
Fe-depleted & $0 \pm 0.00^{* *}$ & $0.17 \pm 0.17$ & $0.50 \pm 0.22$ \\
\hline
\end{tabular}

Data are mean $\pm \mathrm{SE} ; n=6$ in each group.

${ }^{\star} p<0.05$ vs other groups; ${ }^{\star \star} p<0.05$ vs control. 
Likewise, the urinary NOx excretion factored per mg of creatinine was higher in Fe-depleted animals (Fig. 2). No differences were found in plasma NOx concentration among the three groups (Fig. 2).

\section{Morphologic and Lectin Studies}

The extent and pattern of iron deposits in the kidneys are depicted in Figure 3 and Table 2. Figure 3, A to C, represents double stains for iron and lectin Arachis hypogaea $(\mathrm{AH})$, a distal nephron marker. The control rats showed only trace amounts of detectable iron by iron stain (Fig. 3A). No iron deposition was observed in the kidneys of Fe-depleted animals (Fig. 3B). In contrast, the Fe-loaded rats displayed marked iron deposits in the tubules of the cortex and outer medulla. The glomeruli also revealed significant iron deposits, largely in the visceral and parietal epithelial cells (Fig. $3 \mathrm{C)}$.

Lectin studies demonstrated that heavy iron deposition was essentially located in the proximal tubules. The iron staining in the distal tubules ( $\mathrm{AH}$-positive) was negligible (Fig. 3, A and $\mathrm{C}$ ). In addition, scattered interstitial cells showed a heavy iron load.

A mild-to-moderate glomerular injury (sclerosis and collapse of capillary loops) was found in the Fe-loaded animals affecting approximately $20 \%$ of the glomeruli (Fig. 3F) whereas only rare mild focal glomerular changes were noted in the normal controls (Fig. 3D). No significant glomerular abnormalities were appreciated in the Fe-depleted rats (Fig. 3E). A moderate tubular atrophy with cystically dilated tubules filled with proteinatious casts accompanied by mild-tomoderate interstitial fibrosis and lymphocytic infiltration was found in the cortex of Fe-loaded rats (Fig. 3F). In addition, very mild focal tubulointerstitial changes were noted in the control group. The tubulointerstitial changes in Fe-depleted group were essentially negligible (Fig. 3E).

\section{Immunoperoxidase Studies for eNOS and iNOS}

Immunostaining of endothelial nitric oxide synthase (eNOS) was dramatically different for Fe-loaded rats (Fig. 4, A and B) compared with the other groups. There was strong positive staining of endothelial and smooth muscle cells in the small arteries and arterioles. Scattered glomerular cells and proximal tubules were also positive. The rats in the control group (Fig. 4C) and the Fe-depleted group (pictures not shown) revealed eNOS distributions similar to those in the Fe-loaded group, but with much less intensity. eNOS was virtually undetectable in the proximal tubules of these animals. Figure 4, D to F, represents corresponding negative controls.

A similar immunostaining pattern was observed for inducible nitric oxide synthase (iNOS) expression. Animals in the Fe-loaded group showed significantly stronger immunoreaction for iNOS. The signals were localized in the endothelial and smooth muscle cells of small arteries and arterioles, scattered glomerular cells, and peritubular capillaries of the cortex and medulla. Trace amounts of iNOS signal were occasionally noted in the arteries of the control and Fedepleted groups.

\section{Immunoperoxidase Studies for Nitrotyrosine}

In normal control rats, moderate nitrotyrosine expression was seen in the proximal and distal tubules of the renal cortex $(2+)$ (see explanation of ratings in "Materials and Methods") (Fig. 5A, with panel D representing the corresponding negative control). The S3 segments of the proximal tubules were diffusely positive $(2+)$. Collecting ducts in the inner stripe of the outer medulla (ISOM) and in the inner medulla (IM) were also positive $(2+)$. Mild-to-moderate $(1+$ to $2+)$ smooth muscle staining in some of the arterial and arteriolar walls was observed. In addition, there was scattered and weak $(1+)$ staining in glomerular visceral epithelial and endothelial cells. The glomerular mesangial cells were essentially negative.

The Fe-depleted animals showed much less renal staining of nitrotyrosine, and the general distribution of the nitrotyrosine staining was similar to those observed in the control animals $(1+$ in the cortical proximal and distal tubules and in the S3 segment of the proximal tubules) (Fig. 5B, with panel E representing the corresponding negative control). The smooth muscle cells of the arteries showed moderate $(2+)$ staining. The glomeruli were virtually negative.

In contrast, the Fe-loaded animals showed diffuse strong nitrotyrosine expression in the renal cortex in virtually all the proximal and distal tubules $(3+)$ (Fig. $5 \mathrm{C}$, with panel $\mathrm{F}$ representing the corresponding negative control). The S3 segments of the proximal tubules and the collecting ducts in the ISOM and the IM were strongly positive $(3+)$. The smooth muscle cells of the arteries and the arterioles and the endothelial cells demonstrated moderate staining $(2+)$. The glomeruli revealed positive staining in scattered visceral epithelial cells $(1+)$, mesangial cells $(1+)$, and occasional endothelial cells $(1+)$.

\section{Correlations}

Significant direct correlations were found between renal injury scores and plasma and renal tissue MDA concentration in the entire study population (Fig. 6).

\section{Discussion}

Animals exposed to high levels of iron exhibited a significant renal damage characterized by glomerulosclerosis, tubular atrophy, and interstitial fibrosis. These observations are consistent with those reported in the previous studies (Landing et al, 1989; PardoMindan et al, 1990; Zhou, et al, 1996). The renal injury in Fe-loaded animals was accompanied by a significant elevation of plasma and renal tissue MDA concentrations, which signify an increased ROS activity leading to enhanced lipid peroxidation. In addition, we have demonstrated a marked up-regulation of renal nitric oxide synthase (NOS) isozyme expression, sug- 

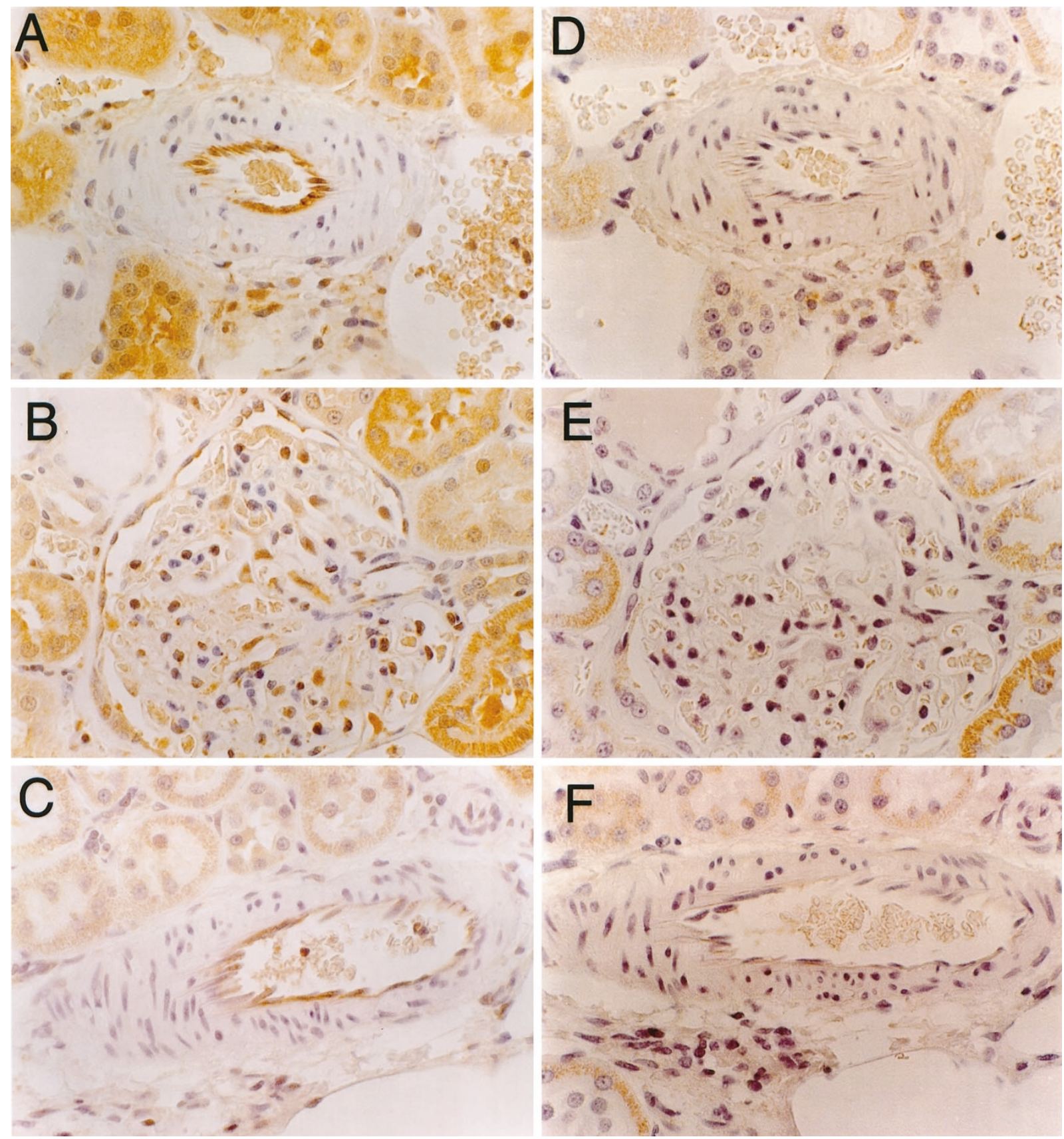

Figure 4.

eNOS immunoperoxidase. Tissue expression of eNOS in the kidneys of Fe-loaded $(A$ and $B)$ and control $(C)$ animals. Photomicrographs on the right $(D$ to $F)$ depict negative controls for the immunohistochemical stains. $A$, Strong endothelial, as well as weak and patchy smooth muscle, eNOS positivity in a small artery. The juxtaposed proximal tubules are also positive. $B$, Positive eNOS stain is seen in some of the visceral epithelial cells and also in the endothelial cells of the glomerulus. The proximal tubular epithelial cells are also positive. C, eNOS expression of the arterial endothelial cells is less intense in the control animals. Note the much weaker proximal tubular epithelial staining when compared with the Fe-loaded group. The staining pattern and intensity in Fe-loaded animals are similar to those of controls

gesting enhanced NO production in this model. The observed up-regulation of NOS isozymes in the face of normal urinary NOx excretion indicates an increased NO inactivation/sequestration in Fe-loaded animals. To this end, we determined renal tissue nitrotyrosine, which is the footprint of NO-ROS interaction. NO vigorously reacts with superoxide $\left(\mathrm{O}_{2}^{-}\right)$ and other ROS to produce peroxynitrite $\left(\mathrm{ONOO}^{-}\right)$, a highly cytotoxic reactive nitrogen species. Peroxynitrite, in turn, reacts vigorously with and damages proteins, lipids, and DNA (Halliwell, 1997). For instance, peroxynitrite reacts with tyrosine residues of proteins to produce nitrotyrosine. Alternatively, ROS can initially react with tyrosine to produce tyrosyl radicals that can, in turn, oxidize $\mathrm{NO}$ and generate nitrotyrosine (Eiserich, et al, 1995). In addition, nitrotyrosine can be formed from an interaction of nitrogen dioxide with the tyrosine residues of proteins (Eiserich, et al, 1998; Halliwell, 1997). However, the contribution of the latter reactions to total tissue nitrotyrosine 

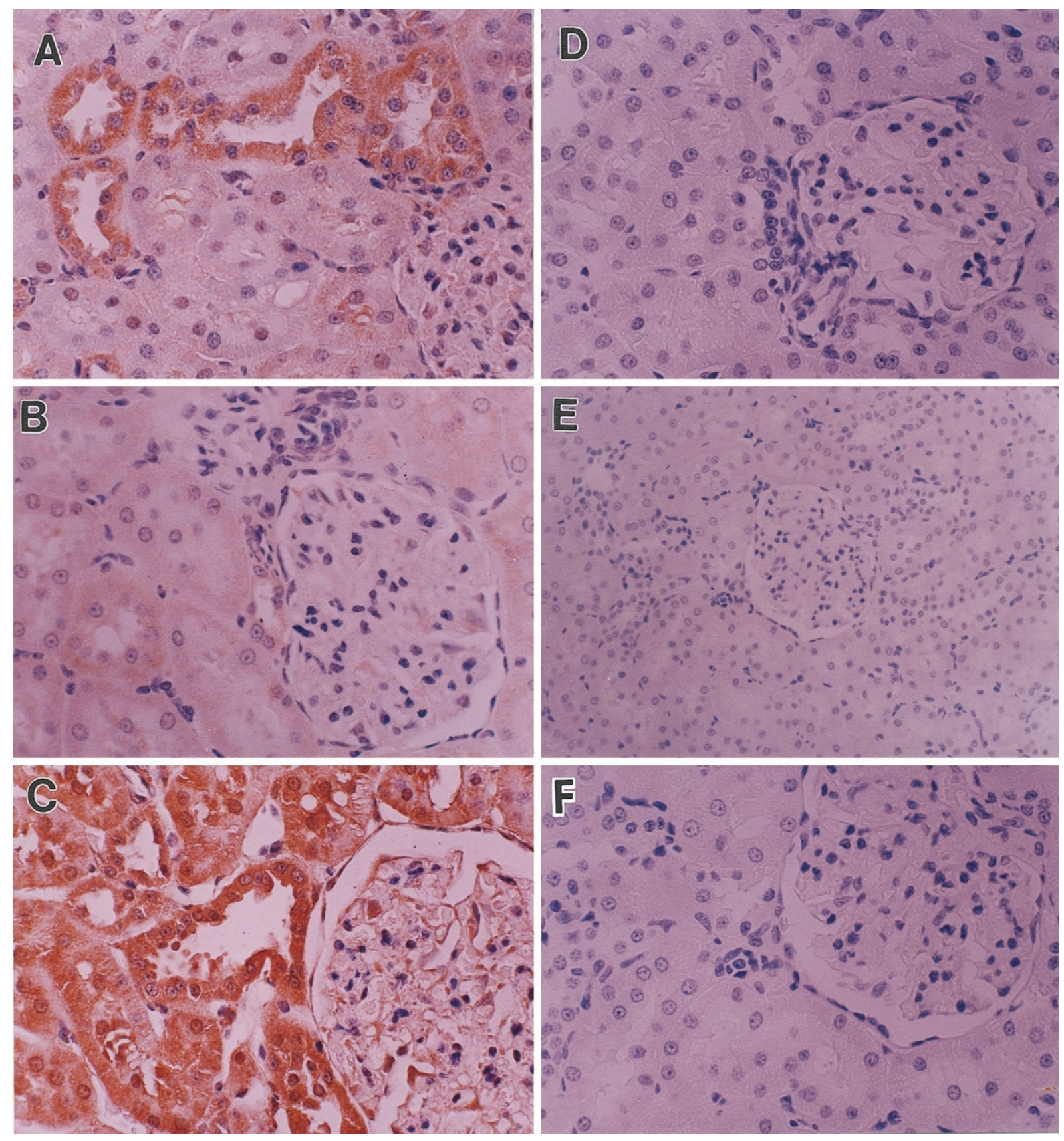

\section{Figure 5.}

Nitrotyrosine immunoperoxidase. Tissue expression of nitrotyrosine in the kidneys of control $(A)$, Fe-depleted $(B)$, and Fe-loaded $(C)$ animals. Photomicrographs on the right $(D$ to $F$ ) depict negative controls for the immunohistochemical stains. $A$, Focal moderate $(2+)$ positivities were shown in scattered cortical tubules (both proximal and distal) with the glomerulus (right corner) being practically negative. $B$, Focal mild $(1+)$ positivities were seen in a few cortical tubules. The glomerulus was negative. C, Diffuse strong (3+) positivities were observed in the cortical tubules. The glomeruli revealed positive staining in scattered visceral epithelial cells, mesangial cells, and endothelial cells.

abundance is limited and, as such, nitrotyrosine abundance is generally considered as an indicator of NO oxidation by ROS (Beckman and Koppenol, 1996). In this study, we demonstrated a marked increase in nitrotyrosine abundance in the kidney in Fe-loaded animals, which provided further evidence of increased ROS activity in these animals. In addition, increased tissue nitrotyrosine burden was necessarily indicative of inactivation and sequestration of NO. The generation of nitrotyrosine, which involves ROS-mediated oxidation of NO, may necessarily limit $\mathrm{NO}$ availability to the kidney. This can, in turn contribute to the up-regulation of NOS isotypes in Fe-loaded animals via a negative feedback influence of NO on NOS expression (Vaziri and Wang, 1999). The results of the present study in Fe-loaded animals mirror those of our recent studies that showed enhanced NO oxidation by ROS coupled with compensatory up-regulation of NOS isotypes in rats with chronic exposure to low levels of lead (Vaziri et al, 1999a, 1999b). 


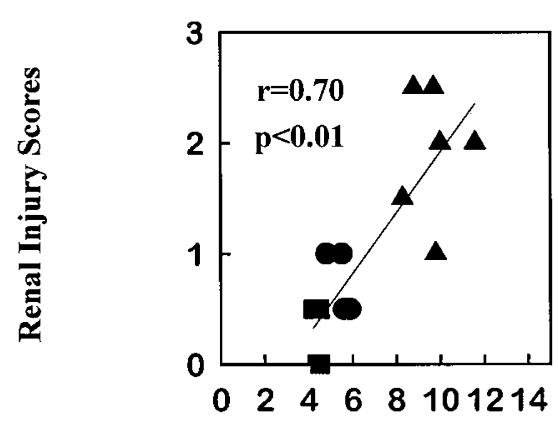

Plasma MDA Concentration $(\mu \mathrm{M} / \mathrm{L})$

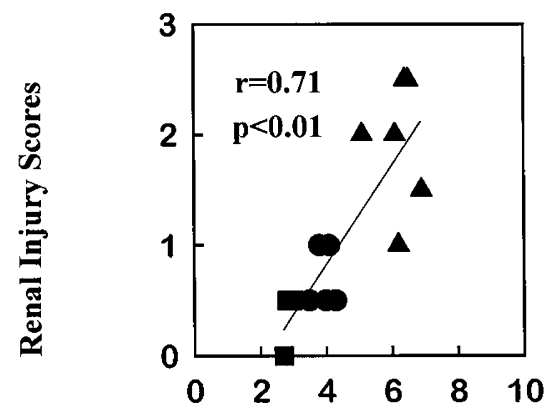

Kidney MDA Concentration $(\mu \mathrm{M} / \mathrm{L})$

Figure 6.

Correlation between renal injuries and plasma MDA (upper panel) and renal tissue MDA (lower panel) levels in the control $(\mathbf{0})$, Fe-loaded ( $\mathbf{\Delta})$, and Fe-depleted ( $\square$ ) animals. $n=6$ in each group.

In several experimental models, iron has been identified as the cause of renal injury including toxic (Paller, 1988; Shah and Walker, 1988; Thakur et al, 1988; Walker and Shah, 1988), ischemic (Paller and Hedlund, 1988), and immunologic (Alfrey et al, 1989) renal diseases. In rats, acute iron loading resulted in lysosomal iron accumulation, ROS generation, and tubular damage (Goldberg et al, 1962). However, the pathophysiology of renal injury associated with the longterm iron overload has not been fully elucidated. In the present study, we have clearly demonstrated a strong positive correlation between tissue iron burden, ROS activity, and the severity of renal injuries, which supports the proposition that renal injury in Fe-loaded animals may be directly and/or indirectly mediated by excess production of ROS. In fact, Fe-depleted animals showed no discernible renal lesions; they also showed depressed tissue MDA and nitrotyrosine levels, significantly increased urinary NOx excretion, and normal NOS expression. The rise in urinary NOx excretion in the iron-depleted animals was not due to enhanced glomerular clearance of these metabolites because iron depletion did not raise the glomerular filtration rate and did not lower the plasma NO con- centration. It should also be noted that the increase in urinary NOx in the Fe-depleted rats was not due to increased dietary nitrate/nitrite or L-arginine contents because the Fe-depleted rats consumed less food when compared with the control and Fe-loaded animals. In addition, normal NOS expressions found here indicate normal NO production in Fe-depleted animals. Hence, the increased $\mathrm{NO}$ availability in Fedepleted animals is, at least in part, due to reduced NO inactivation by ROS as evidenced by low MDA and nitrotyrosine levels. The renoprotective effect of iron depletions is supported by several other studies in various models of renal injuries (Alfrey et al, 1989; Nankivell et al, 1994; Paller, 1988; Paller and Hedlund, 1988; Remuzzi et al, 1991; Shah, 1988; Shah and Walker, 1988; Walker and Shah, 1988).

Elevation of MDA and nitrotyrosine abundance in the renal tissue point to increased ROS activity and enhanced NO inactivation/sequestration, which in turn diminish NO availability (Vaziri et al, 1999a, 1999b). In fact, the presence of nitrotyrosine in the kidney has been associated with renal injuries of experimental glomerulonephritis (Heeringa et al, 1998), human renal allograft rejection (MacMillan-Crow et al, 1996), leadinduced nephrotoxicity (Vaziri et al, 1999a, 1999b), and the Goldblatt animal model of hypertension (Bosse and Bachmann, 1997). In addition, the direct injurious effect of ROS may be augmented by the associated decline in NO availability. For instance, reduced regional NO availability can cause glomerular hypertension, which contributes to the pathogenesis of glomerular sclerotic injury in a variety of glomerular diseases (Brenner, 1985). In addition, the diminished inhibitory action of NO on mesangial cell proliferation and matrix production (Garg and Hassid, 1989; Trachtman et al, 1995) may promote mesangial cell proliferation and matrix accumulation leading to glomerulosclerosis. Finally, as the major endogenous antagonist of the vascular action of Ang II, ROSmediated reduction in NO availability may lead to Ang II-mediated vasoconstriction, mesangial cell proliferation, and matrix accumulation (Raij, 1998).

The precise distribution of iron deposits in the renal tubular system has been controversial. Studies in humans with iron overload caused by various diseases have shown widespread distribution of deposits in the proximal tubules, ascending limb, and the distal and collecting tubules (Landing et al, 1989). The distribution of hemosiderin in the tubules may be related to the nature of the underlying disease or to the associated hemodynamic factors in a given patient. Normally, the periodic acid-Schiff-positive brush border and the characteristic morphologic features allow the distinction between proximal and distal tubules by light microscopy. Under some pathologic conditions, the light microscopic distinction between the proximal and distal tubules frequently becomes impossible, and before the advent of nephron segment-specific markers, the differential involvement of the different renal tubular segments in iron overload was not well established. In the present study, we elected to use lectin immunohistochemistry, which is a sensitive 
method for identification of tubular segments despite a severe distortion of tubular morphology in Fe-loaded animals. To our surprise, we found that iron is essentially localized in the proximal tubules with negligible amounts found in distal tubules in this animal model. It is therefore plausible that, at least in some of the previous studies, iron deposits described in the distal tubules might have actually represented deposits in the morphologically distalized proximal tubules. The precise reason for the predominance of iron deposition in proximal tubules is not entirely clear. It has been suggested that the reabsorption and catabolism of filtered iron-containing proteins occur in the proximal tubules, which may account for this phenomenon (Trump et al, 1973).

In conclusion, chronic iron overload resulted in various renal lesions coupled with increased ROS activity, diminished NO availability, and compensatory up-regulation of renal eNOS and iNOS expressions. In contrast, iron depletion was associated with reduced ROS activity, enhanced NO availability, increased urinary NOx excretion, and total absence of renal pathology. These findings might point to the role of ironinduced oxidative stress in the pathogenesis of renal lesions in animals with experimental hemosiderosis.

\section{Materials and Methods}

Male Sprague-Dawley rats (Charles River Inc., Wilmington, Massachusetts) with the average weight of $290 \mathrm{~g}$ were used. They were allowed free access to food (Purina Test Diet; Purina, Richmond, Indiana) and water and were randomized into Fe-loaded and $\mathrm{Fe}$ depleted groups. Animals placed in the Fe-loaded group received a single iv injection of an iron-dextran complex (Sigma Chemical Company, St. Louis, Missouri) at a dose of $0.5 \mathrm{~g}$ elemental iron/ $\mathrm{kg}$ body weight. Iron depletion was induced by feeding the animals an iron-free diet (Purina Test Diet) for 20 weeks beginning at 4 weeks of age. A group of normal animals was included for comparison. Animals were kept for 20 weeks in a university animal research facility. Except for iron contents, the chemical compositions are identical in the iron-free and control diets.

\section{Measurements of Plasma and Urine $\mathrm{NO}_{2}^{-} / \mathrm{NO}_{3}^{-}\left(\mathrm{NO}_{x}\right)$}

The amounts of total nitrate and nitrite in the test samples were determined as described earlier (Vaziri et al, 1998; Zhou et al, 2000) using the purge system of a Model 270B Nitric Oxide Analyzer (Sievers Instruments Inc., Boulder, Colorado).

\section{Renal Tissue and Plasma MDA Assay}

Lipoperoxides in renal tissue and plasma were determined by measurement of malondialdehydethiobarbituric acid (MDA-TBA) using a modification of the method of Ohkawa et al (1979). Briefly, the kidney was removed and washed with PBS and subsequently homogenized in $3 \mathrm{ml}$ of $100 \mathrm{mM}$ potassium chloride containing 0.003 M EGTA. The homogenized tissue was centrifuged at $600 \mathrm{~g}$ for 15 minutes. The super- natant was saved for the measurement of MDA. The supernatant or plasma $(0.4 \mathrm{ml})$ was added to a reaction mixture consisting of $0.2 \mathrm{ml}$ of $8.1 \%$ SDS, $1.5 \mathrm{ml}$ of $20 \%$ acetic acid, $1.5 \mathrm{ml}$ of $0.8 \%$ thiobarbituric acid, and $6.6 \mathrm{ml}$ of water. The solution was incubated in a water bath at $95^{\circ} \mathrm{C}$ for 80 minutes. After removal and cooling, $1 \mathrm{ml}$ of water and $5 \mathrm{ml}$ of $\mathrm{n}$-butanol pyridine mixture (15:1 vol/vol) were added. The samples were centrifuged at $1800 \mathrm{~g}$ for 20 minutes. The organic layer was removed by pipette, and absorbance of this fraction was read at $532 \mathrm{~nm}$. The tetramethoxypropane (TMP) was employed as the standard. The amount of MDA was expressed per milligram of protein. Protein content was determined using bicinchoninic acid (BCA) assay.

\section{Histologic Examinations and Lectin Histochemistry}

Six animals in each group were exsanguinated for morphological studies. Immediately after exsanguination, the kidneys were removed and promptly sectioned and separately postfixed in 10\% buffered formalin. The fixed tissue was embedded in paraffin and sectioned. The sections were stained with Gomori's iron stain, Masson's trichrome stain, periodic acidSchiff stain, and hematoxylin and eosin.

To determine the precise locations of hemosiderin deposition, lectin studies were performed as detailed previously (Silva et al, 1993). Briefly, two peroxidaselabeled lectins, Tetragonolobus purpureas (TP) and Arachis hypogaea $(\mathrm{AH})$ (both from Sigma Chemical Company), were used as markers of the proximal renal tubular epithelium and distal nephron (distal convoluted tubule and collecting duct), respectively.

The degree of iron deposition was estimated by a semiquantitative morphological analysis using the following scales: 0 , none; $1+$, mild; $2+$, moderate; and $3+$, marked. The results of tissue damage were scored semiquantitatively. Briefly, a minimum of 100 nephrons in each renal specimen was examined. Glomeruli with any degree of sclerosis or collapse and thrombonecrotic lesions were graded as follows: 0 , $0 \% ; 1+, 1 \%$ to $10 \% ; 2+, 11 \%$ to $20 \% ; 3+, 21 \%$ to $30 \% ; 4+, 31 \%$ or greater. Tubulointerstitial lesions were scored on the basis of tubular atrophy and dilatation and interstitial fibrosis as follows: 0 , no lesions; $1+$, very mild focal dilation and/or very few foci of tubular atrophy; $2+$, larger number of dilated tubules with widening of interstitium and/or larger number of foci of tubular atrophy; $3+$, extensive dilation of tubules with cyst formation and widening of interstitium and/or a large number of foci of tubular atrophy; 4+, atrophy of tubules.

\section{Immunoperoxidase Studies}

Immunohistochemical stainings for eNOS, iNOS, and nitrotyrosine were performed using a standardized streptavidin-biotin-peroxidase method on formalinfixed paraffin-embedded renal tissues (Zhou et al, 2000). Except for the incubation with the primary antibodies, all incubations were at room temperature 
and were separated by washes with phosphate buffered saline (PBS). After deparaffinization, sections were treated with $1.25 \%$ hydrogen peroxidase to block endogenous peroxidase activity. After preincubation with $10 \%$ normal horse or swine serum for 20 minutes, sections were incubated with primary antibodies overnight at $4^{\circ} \mathrm{C}$, followed sequentially with biotinylated horse antimouse (Vector Laboratories, Burlingame, California) or biotinylated swine antirabbit (Dako Corporation, Carpinteria, California) antibodies for 20 minutes, and streptavidin-peroxidase complex (Dako) for 30 minutes. The working concentrations for the mouse anti-eNOS monoclonal antibody (Transduction Laboratories, Lexington, Kentucky), rabbit anti-iNOS antibody (Transduction), and rabbit antinitrotyrosine antibody (Upstate Biotechnology, Inc., Lake Placid, New York) were $0.05 \mu \mathrm{g} / \mathrm{ml}, 0.025 \mu \mathrm{g} / \mathrm{ml}$, and $5.9 \mu \mathrm{g} / \mathrm{ml}$, respectively. For negative controls, a monoclonal mouse IgG1 (Bethyl Laboratories Inc., Montgomery, Texas) or normal rabbit serum was used at equivalent concentrations. Diaminobenzidine (Sigma) was used as chromogen, and hematoxylin was used for nuclear counterstain. The intensity of immunohistochemical signal for various antibodies was estimated semiquantitatively using the following scales: 0 , none; $1+$, mild; $2+$, moderate; and $3+$, marked.

\section{Data Analysis}

Data are presented as mean \pm SEM. Analysis of variance (ANOVA) and regression analysis were used in evaluation of the data as appropriate. $P$ values equal to or less than 0.05 were considered significant.

\section{References}

Alfrey AC, Froment DH, and Hammond WS (1989). Role of iron in the tubulo-interstitial injury in nephrotoxic serum nephritis. Kidney Int 36:753-759.

Bacon BR and Britton RS (1989). Hepatic injury in chronic iron overload. Role of lipid peroxidation. Chem Biol Interact 70:183-226.

Baylis C, Mitruka B, and Deng A (1992). Chronic blockade of nitric oxide synthesis in the rat produces systemic hypertension and glomerular damage. J Clin Invest 90:278-281.

Beckman JS and Koppenol WH (1996). Nitric oxide, superoxide, and peroxinitrite: The good, the bad, and ugly. Am J Physiol 271:C1424-C1437.

Bosse HM and Bachmann S (1997). Immunohistochemically detected protein nitration indicates sites of renal nitric oxide release in Goldblatt hypertension. Hypertension 30:948-952.

Brenner BM (1985). Nephron adaptation to renal injury or ablation. Am J Physiol 249:F324-F337.

Edwards CQ, Griffen LM, and Kushner JP (1991). Disorders of excess iron. Hosp Pract (Off Ed) 26(Suppl):30-36.

Eiserich JP, Butler J, Van Der Vliet A, Cross CE, and Halliwell $B$ (1995). Nitric oxide rapidly scavenges tyrosine and tryptophan radicals. Biochem J 310:745-749.

Eiserich JP, Hristova M, Cross CE, Jones AD, Freeman BA, Halliwell B, and Van Der Vliet A (1998). Formation of nitric oxide-derived inflammatory oxidants by myeloperoxidase in neutrophils. Nature 391:393-397.

Fujihara CK, Michellazzo SM, DeNucci G, and Zatz R (1994). Sodium excess aggravates hypertension and renal parenchymal injury in rats with chronic NO inhibition. Am J Physiol 266:F697-F705.

Garg UC and Hassid A (1989). Inhibition of rat mesangial cell mitogenesis by nitric oxide-generating vasodilators. Am J Physiol 257:F60-F66.

Goldberg L, Martin LE, and Batchelor A (1962). Biochemical changes in the tissue of animals injected with iron: 3 . Lipid peroxidation. Biochem J 83:291-298.

Gonick HC, Cohen AH, Ren Q, Saldanha LF, Khalil-Manesh F, Anzalone J, and Sun YY (1996). Effect of 2:3dimercaptosuccinic acid on nephrosclerosis in the Dahl rat. I. Role of reactive oxygen species. Kidney Int 50:1572-1581.

Halliwell B (1997). What nitrates tyrosine? Is nitrotyrosine specific as a biomarker of peroxynitrate formation in vivo? FEBS Lett 411:157-160.

Halliwell B and Gutteridge JM (1985). The importance of free radicals and catalytic metal ions in human disease. Mol Aspects Med 8:89-193.

Heeringa P, van Goor H, Moshage H, Klok PA, Huitema MG, Jager AD, Schep AJ, and Kallenberg CGM (1998). Expression of iNOS, eNOS, and peroxynitrite-modified proteins in experimental anti-myeloperoxidase associated cresentic glomerulonephritis. Kidney Int 53:382-393.

Landing BH, Gonick HC, Nadorra RL, Hyman CB, Wells TR, Villarreal-Engelhardt G, Mersch J, and Agness CL (1989). Renal lesions and clinical findings in thalassemia major and other chronic anemias with hemosiderosis. Pediatr Pathol 9:479-500.

MacMillan-Crow LA, Crow, JP, Kerby, JD, Beckman JS, and Thompson JA (1996). Nitration and inactivation of manganese superoxide dismutase in chronic rejection of human renal allografts. Proc Natl Acad Sci USA 93:11853-11858.

Myers SI, Hernandez R, and Castaneda A (1995). Possible role for oxygen free radicals in the regulation of renal nitric oxide synthesis and blood flow. Am J Surg 169:604-608.

Nankivell BJ, Chen J, Boadle RD, and Harris DCH (1994). The role of tubular iron accumulation in the remnant kidney. $\mathrm{J} \mathrm{Am}$ Soc Nephrol 4:1598-1607.

Ohkawa H, Ohishi N, and Yagi K (1979). Assay for lipid peroxides in animal tissues by thiobarbituric acid reaction. Anal Biochem 95:351-358.

Paller MS (1988). Hemoglobin and myoglobin-induced acute renal failure in rats: Role of iron in nephrotoxicity. Am J Physiol 255:F539-F544.

Paller MS and Hedlund BE (1988). Role of iron in postischemic renal injury in the rat. Kidney Int 34:474-480.

Pardo-Mindan FJ, Diez J, Esparza N, and Robledo C (1990). Renal siderosis in patients with heart-valve prostheses: Clinical implications. Nephrol Dial Transplant 5:847-850.

Preece NE, Evans PF, Howarth JA, King LJ, and Parker DV (1988). The induction of autooxidative tissue damage by iron nitrilotriacetate in rats. Toxicol Appl Pharmacol 93:89-100.

Raij $L$ (1998). Nitric oxide in hypertension: Relationship with renal injury and left ventricular hypertrophy. Hypertension 31:189-193. 
Remuzzi A, Puntoreiri S, Brugnetti B, Vertani T, and Remuzzi $G$ (1991). Renoprotective effect of low iron diet and its consequence on glomerular hemodynamics. Kidney Int 39: 547-652.

Ribeiro MO, Antunes E, De-Nucci G, Lovisolo SM, and Zatz R (1992). Chronic inhibition of nitric oxide synthesis: A new model of arterial hypertension. Hypertension 20:298-303.

Shah SV (1988). Evidence suggesting a role for hydroxyl radical in passive Heymann nephritis in rats. Am J Physiol 254:F337-F344.

Shah S (1989). Role of reactive oxygen metabolites in experimental glomerular disease. Kidney Int 35:1093-1106.

Shah SV and Walker PD (1988). Evidence suggesting a role for hydroxyl radical in glycerol-induced acute renal failure. Am J Physiol 255:F438-F443.

Silva FG, Nadasdy T, and Laszik Z (1993). Immunohistochemical and lectin dissection of the human nephron in health and disease. Arch Pathol Lab Med 117:1233-1239.

Thakur V, Walker PD, and Shah SV (1988). Evidence suggesting a role for hydroxyl radical in puromycin aminonucleosideinduced proteinuria. Kidney Int 34:494-499.

Trachtman H, Futterweit S, and Singhal P (1995). Nitric oxide modulates the synthesis of extracellular matrix proteins in cultured rat mesangial cells. Biochem Biophys Res Commun 207:120-125.

Trump BV, Valigorsky JM, Arstila AU, Mergner WJ, and Kinney TD (1973). The relationship of intracellular pathways of iron metabolism to cellular iron overload and the iron storage diseases. Cell sap and cytocavitary network pathways in relation to lysosomal storage and turnover of iron macromolecules. Am J Pathol 72:295-336.
Vaziri ND, Ding Y, and Ni Z (1999a). Nitric oxide synthase expression in the course of lead-induced hypertension. Hypertension 34:558-562.

Vaziri ND, Liang K, and Ding Y (1999b). Increased nitric oxide inactivation by reactive oxygen species in lead-induced hypertension. Kidney Int 56:1492-1498.

Vaziri ND, Ni Z, Wang XQ, Oreisi F, and Zhou XJ (1998). Downregulation of nitric oxide synthase in chronic renal insufficiency: Role of excess PTH. Am J Physiol 274:F642F649.

Vaziri ND and Wang XQ (1999). CGMP-mediated negativefeedback regulation of endothelial nitric oxide expression by nitric oxide. Hypertension 34:1237-1241.

Walker PD and Shah SV (1988). Evidence suggesting a role for hydroxyl radical in passive gentamicin-induced acute renal failure in rats. J Clin Invest 81:334-341.

Yamada SS, Sassaki AL, Fujihara CK, Malheiros DM, DeNucci G, and Zatz R (1996). Effect of salt intake and inhibitor dose on arterial hypertension and renal injury induced by chronic nitric oxide blockade. Hypertension 27:1165-1172.

Zhou XJ, Vaziri ND, Pandian D, Wang ZQ, Mazowiecki M, Liao SY, and Oveisi F (1996). Urinary concentrating defect in experimental hemochromatosis. J Am Soc Nephrol 7:128134.

Zhou XJ, Laszik Z, Ni Z, Wang XQ, Brackett DJ, Lerner MR, Silva FG, and Vaziri ND (2000). Downregulation of renal nitric oxide synthase expression in experimental thrombotic microangiopathy. Lab Invest 80:1079-1087. 